\title{
Calculation and Analysis of Permanent Magnet Eddy Current Loss Fault with Magnet Segmentation
}

\author{
Bing Li and Ming Li \\ College of Engineering, Bohai University, Jinzhou 121013, China \\ Correspondence should be addressed to Bing Li; libinger521@163.com
}

Received 16 January 2016; Accepted 5 April 2016

Academic Editor: Wen Chen

Copyright (C) 2016 B. Li and M. Li. This is an open access article distributed under the Creative Commons Attribution License, which permits unrestricted use, distribution, and reproduction in any medium, provided the original work is properly cited.

\begin{abstract}
This paper investigates the problem of calculating and analyzing the effect of the permanent magnet eddy current loss fault due to magnet segmentation. Taking an interior permanent magnet synchronous motor with inverter supplied as an example, the rated power of motor was $2.2 \mathrm{~kW}$. Three-dimensional finite-element model was firstly established based on finite-element software. Then, the model mesh and boundary conditions were handled specially; permanent magnet eddy current loss fault was calculated and analyzed theoretically with magnet segmentation from space harmonic and time harmonic, respectively. Finally, calculation results were compared and explained. A useful conclusion for permanent magnet synchronous motor design has been obtained.
\end{abstract}

\section{Introduction}

With the development of power electronic devices and the improvement of the motor control technology, the permanent magnet synchronous motor has attracted more and more attention for its advantages of high efficiency, wide speed regulation, and high power density. But with the increase of the power density, it is worthy of considering how to make the motor temperature rise in the range of allowable limit value. Reducing the temperature rise of the motor should start from two aspects: how to improve the cooling capacity of motor and how to reduce the loss of motor. Because of the high speed and large carrier frequency of the permanent magnet synchronous motor, the eddy current loss of the permanent magnet is large.

In order to reduce the eddy current loss of permanent magnet, researchers have conducted a lot of research [1-5]. Among the studies, the axial section method of permanent magnet is widely accepted. Based on the previous research, the eddy current loss of interior permanent magnet synchronous motor is studied in this paper. Taking an interior permanent magnet synchronous motor with a rated power $2.2 \mathrm{~kW}$ as an example, a three-dimensional (3D) finiteelement model is established. Permanent magnet eddy current loss fault was calculated and analyzed theoretically with magnet segmentation from space harmonic and time harmonic, respectively; at the same time, the finite-element method is verified by analytic method.

One of the main problems of $\mathrm{NdFeB}$ permanent magnet synchronous motor is thermal demagnetization, which is caused by the permanent magnet eddy current loss. In particular, the permanent magnet AC servomotor is mostly used in the fractional slot concentrated winding whose magnetic motive force (MMF) harmonic content is very rich [6]. Thus, reducing the eddy current loss of permanent magnet has attracted more and more attention, in which the axial section of the pole is used to reduce the eddy current loss of the permanent magnet [7-9]. It is widely adopted by the designers of the motor.

There are two reasons for permanent magnet to generate eddy current losses [10-12]. One is the slotted stator and stator winding distribution caused by uneven distribution of MMF and the space harmonic. The second is the nonsinusoidal time harmonic of the stator current caused by inverter power supply. Permanent magnet eddy current losses can be expressed as

$$
P_{\mathrm{mag}}=\sum_{k} \frac{J_{k}^{2}}{\sigma} d v .
$$




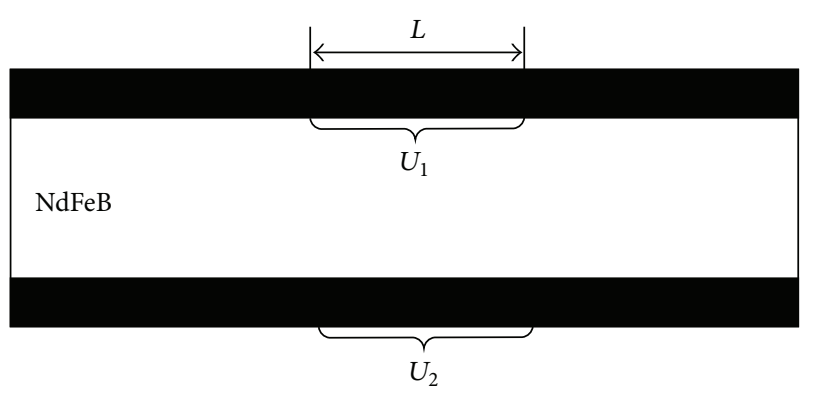

FIGURE 1: Surface potential difference of permanent magnet.

\section{Analysis and Calculation of Eddy Current Loss of Permanent Magnet of Interior Permanent Magnet Motor}

Suppose there is an infinite neodymium iron boron permanent magnet; the external magnetic field is parallel to the surface in the direction of the $z$-axis; the vortex at a certain point in the permanent magnet can be decomposed into two mutually perpendicular eddy current densities; it can be determined by

$$
J_{e}=\frac{\sigma U}{L}
$$

where $J_{e}$ is eddy current density, $\sigma$ is electrical conductivity of permanent magnet materials, $U$ is the voltage between the nodes in the calculation unit, and $L$ is distance between nodes in a computing unit. As shown in Figure 1, suppose the potential difference between two points on the two sides of the permanent magnet block is $U_{1}, U_{2}$. For easy calculation, it can be set as $U_{1}=U_{2}=U$. The potential difference of the permanent magnet in the thickness direction is ignored again.

The total voltage of the 4 points on the surface of the permanent magnet which is composed of the two ends of the loop is

$$
2 U(t)=\frac{d \phi(t)}{d t}=\frac{A d B(t)}{d t},
$$

where $A$ is loop area and $B(t)$ is magnetic density in the circuit; it can be expressed as

$$
B(t)=B_{0}+B_{a}
$$

where $B_{0}$ is static magnetic density and $B_{a}$ is dynamic magnetic flux induced by stator armature current. $B_{a}$ is regarded as a nonsinusoidal periodic function; the trigonometric series of $B_{a}$ is decomposed into Fourier series:

$$
B_{a}=\sum_{n=1}^{\infty}\left(a_{n} \cos n \omega t+b_{n} \sin n \omega t\right),
$$

where $a_{n}$ and $b_{n}$ are the amplitude of the dynamic magnetic flux generated by the harmonic component of the armature current in the permanent magnet.
Then,

$$
\begin{aligned}
\frac{d B(t)}{d t} & =\frac{d\left(B_{0}+B_{a}\right)}{d t} \\
& =\sum_{n=1}^{\infty} n \omega\left(b_{n} \cos n \omega t-a_{n} \sin n \omega t\right), \\
2 U(t) & =\frac{A d B(t)}{d t}=A \sum_{n=1}^{\infty} n \omega\left(b_{n} \cos n \omega t-a_{n} \sin n \omega t\right) .
\end{aligned}
$$

The effective value of $U(t)$ is

$$
\begin{aligned}
U & =\frac{\omega A}{2} \cdot \sqrt{\sum_{n=1}^{\infty} \frac{n^{2}\left(a^{2}+b^{2}\right)}{2}} \\
& =A \pi f \cdot \sqrt{\sum_{n=1}^{\infty} \frac{n^{2}\left(a^{2}+b^{2}\right)}{2}} .
\end{aligned}
$$

According to formula (7), the eddy current density in the permanent magnet is obtained:

$$
\begin{aligned}
J_{e} & =\frac{\omega f \sigma A}{L} \cdot \sqrt{\sum_{n=1}^{\infty} \frac{n^{2}\left(a^{2}+b^{2}\right)}{2}} \\
& =\pi f \sigma h_{m} \cdot \sqrt{\sum_{n=1}^{\infty} \frac{n^{2}\left(a^{2}+b^{2}\right)}{2}}
\end{aligned}
$$

where $h_{m}$ is permanent magnet magnetization direction length, so the eddy current loss power density of the permanent magnet can be obtained:

$$
P_{e}=\frac{J_{e}^{2}}{\sigma}=\pi^{2} f^{2} \sigma h_{m}^{2} \cdot \sum_{n=1}^{\infty} \frac{n^{2}\left(a^{2}+b^{2}\right)}{2} .
$$

Eddy current loss density is

$$
W_{e}=\pi^{2} f \sigma h_{m}^{2} \cdot \sum_{n=1}^{\infty} \frac{n^{2}\left(a^{2}+b^{2}\right)}{2} .
$$

Eddy current loss density of permanent magnet is integral and then it can get eddy current loss in permanent magnet.

\section{Effect of Pole Axial Section on the Eddy Current Loss Fault of Permanent Magnet Produced by Space Harmonic Generation}

The basic parameters of an interior permanent magnet synchronous motor with a rated power $2.2 \mathrm{~kW}$ in this paper are shown in Table 1 . The $3 \mathrm{D}$ model of motor is constructed by using the finite-element analysis software. In order to save the computing resources, coupled with cycle magnetic distribution, a unit of the motor is modeled and calculated. Figure 2 shows 3D finite-element mesh model of a $2.2 \mathrm{~kW}$ permanent magnet synchronous motor. 
TABLE 1: Parameters of $2.2 \mathrm{~kW}$ motor and permanent magnet.

\begin{tabular}{|c|c|}
\hline Rated power $/ \mathrm{kW}$ & 2.2 \\
\hline Phase number & 3 \\
\hline Poles number & 8 \\
\hline Stator outer diameter $/ \mathrm{mm}$ and inter diameter $/ \mathrm{mm}$ & 155,98 \\
\hline Stator slot number & 36 \\
\hline $\begin{array}{l}\text { Permanent magnet material and electrical } \\
\text { conductivity } / \mathrm{s} \cdot \mathrm{m}^{-1}\end{array}$ & $\begin{array}{l}\text { Nd-Fe-B, } \\
6.9 \times 10^{5}\end{array}$ \\
\hline Residual magnetic flux density/T & $B_{r}=1.18$ \\
\hline Permanent magnet size/mm & $60 \times 33 \times 3$ \\
\hline
\end{tabular}

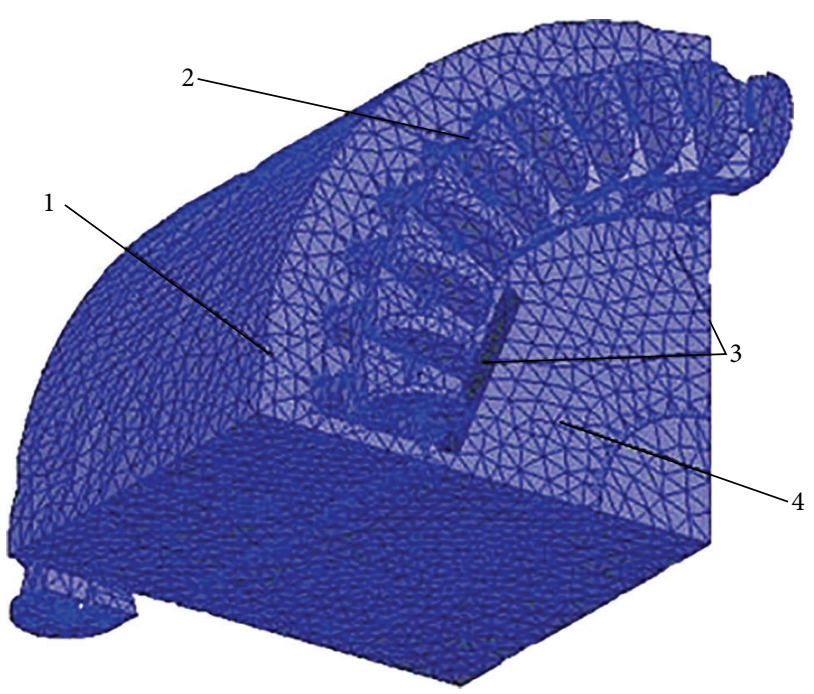

FIGURE 2: 3D sectional drawing of $2.2 \mathrm{~kW}$ permanent magnet synchronous motor ( 1 is the stator, 2 is the windings, 3 is the permanent magnet, and 4 is the rotor).

In order to keep the consistency for carrying on mesh each time, the 3D model is set up by the insulation boundary condition and the zero excitation. The eddy current loss of the permanent magnets which are divided into different segments is calculated under the condition of no load. The results are shown in Figure 3 and Table 2.

From Figure 3, the vortex line is cut off by the axial section of the permanent magnet, and it is formed locally in the section of the magnetic pole. In comparison with Table 2, the mean of eddy current loss increases with the number of magnetic poles.

\section{Effect of Pole Axial Section on the Eddy Current Loss of Permanent Magnet Produced by Time Harmonic Generation}

Permanent magnet eddy current loss mainly is generated by the time harmonic generation. Literature [13] shows that eddy current loss is the biggest when the axial length of the permanent magnet is equal to 2.3 times the penetration depth. Permanent magnet of the penetration depth can be
TABLE 2: Eddy current losses in different segments of a magnet.

\begin{tabular}{lccc}
\hline Segment & $\begin{array}{c}\text { Maximum eddy } \\
\text { density/A.m }\end{array}$ & $\begin{array}{c}\text { Minimum eddy } \\
\text { density/A.m }\end{array}$ & $\begin{array}{c}\text { Mean value of } \\
\text { eddy current } \\
\text { loss/W }\end{array}$ \\
\hline 1 & 2.01 & $1.83 \times 10^{-9}$ & 0.29 \\
2 & 0.49 & $2.0 \times 10^{-9}$ & 0.13 \\
3 & 0.35 & $0.23 \times 10^{-9}$ & 0.067 \\
4 & 0.68 & $0.78 \times 10^{-9}$ & 0.041 \\
5 & 0.24 & $0.46 \times 10^{-9}$ & 0.021 \\
6 & 0.16 & $0.68 \times 10^{-9}$ & 0.013 \\
\hline
\end{tabular}

defined as the depth of magnetic field act on the inside of the permanent magnet. Magnetic field intensity decreases exponentially with the increase in depth. The penetration depth can be calculated as [14-17]

$$
\delta=\frac{1}{\sqrt{\pi f \mu \sigma}}
$$

where $\delta$ is the permanent magnet penetration depth, $f$ is sinusoidal frequency, $\mu$ is absolute permeability, and $\sigma$ is conductivity.

Figure 4 is the current waveform which is measured by inverter power supply test at rated frequency $f=100 \mathrm{HZ}$. Figure 5 shows the harmonic amplitude after Fourier decomposition. From Figure 4, the harmonic amplitude of the current waveform is smaller at rated speed of the motor.

According to the conclusion of literature [13], this paper selects the 37 th harmonic of current waveform whose permanent magnet penetration depth is about $11.2 \mathrm{~mm}$ corresponding to the 37th harmonic [17-21]. When permanent magnet eddy current loss was calculated by using the ANSOFT software, in order to ensure the synchronous motor work, the eddy current losses in the permanent magnets under the fundamental current and 37th times harmonic current were calculated firstly, and then permanent magnet eddy current loss generated by the fundamental was calculated. The difference between the two results is the permanent magnet eddy current loss by 37 th harmonic.

The eddy current losses of permanent magnets which are segmented into two and three are calculated, and the eddy current losses produced by the thirty-seventh time harmonic current source are shown in Table 3. From Figure 6, the eddy current losses in the different segments of the permanent magnet under the interaction of the fundamental wave and the 37th harmonic can be seen, only the fundamental wave and only the 37 th harmonic. It can be seen that permanent magnet eddy current loss had not been reduced with segments numbers of the permanent magnet increasing from Table 3. When segments numbers of the permanent magnet are three, at this time the ratio of pole axial length and depth of penetration is 1.8 ; the eddy current loss generated by 37 th times harmonic in permanent magnet not only failed to reduce but also increased. 

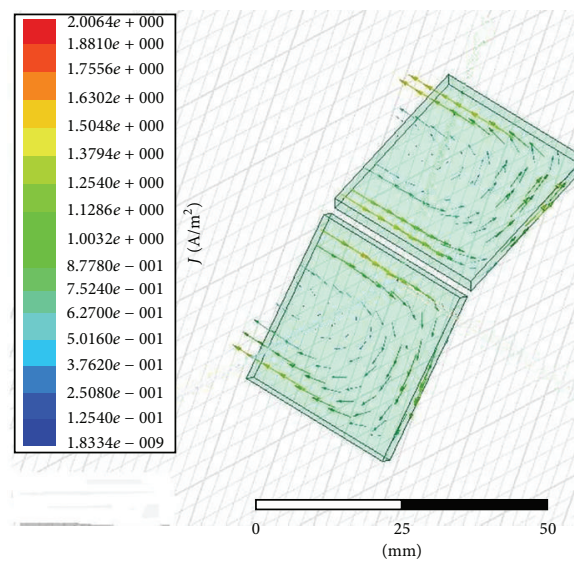

(a)
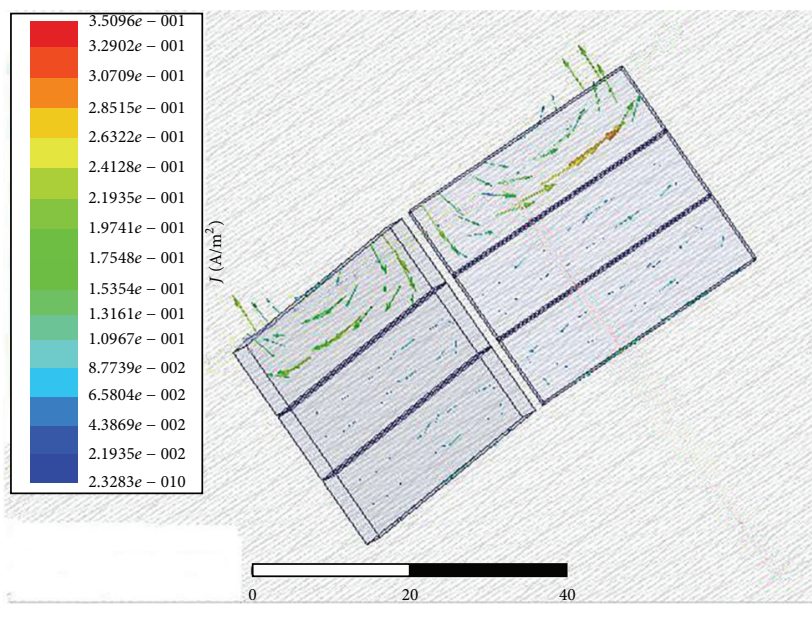

(c)
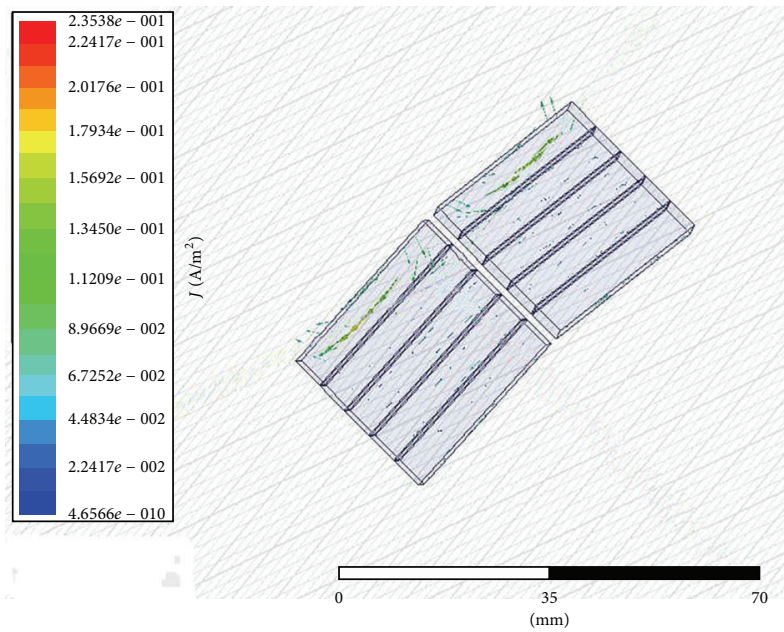

(e)

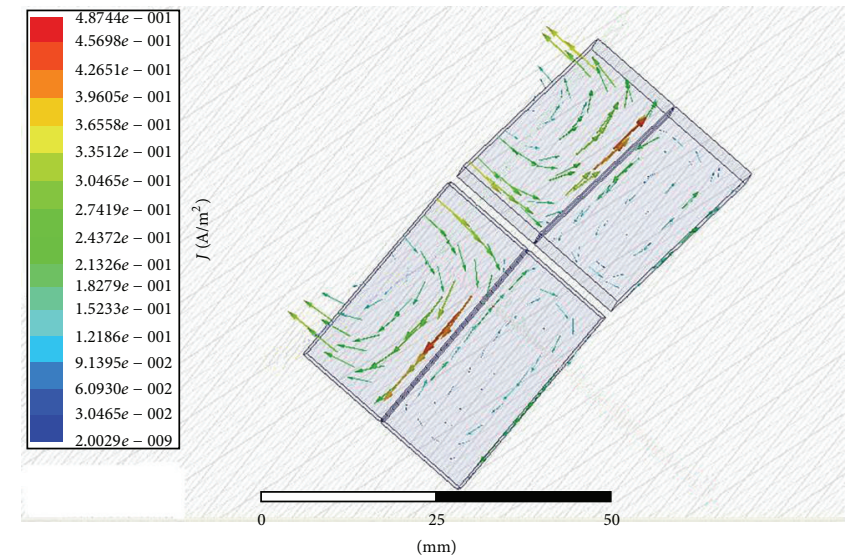

(b)

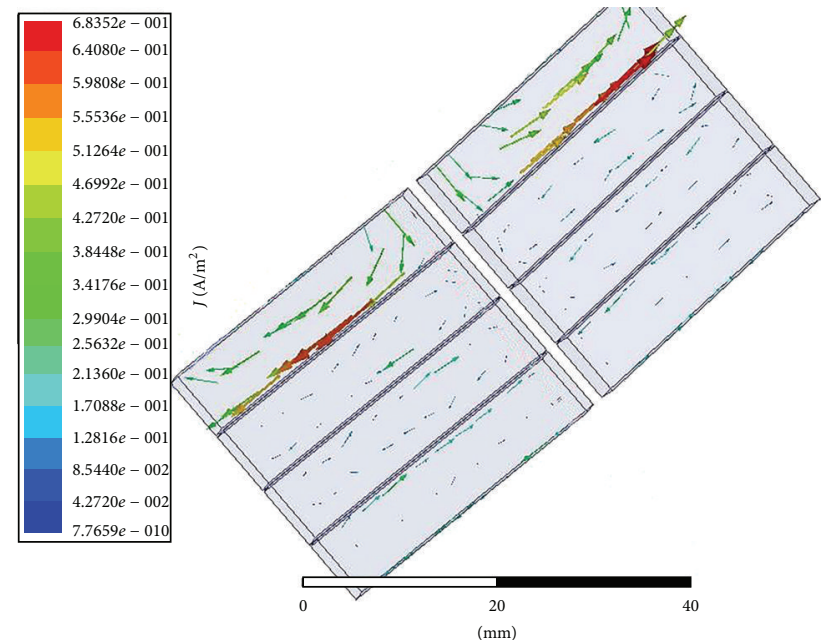

(d)
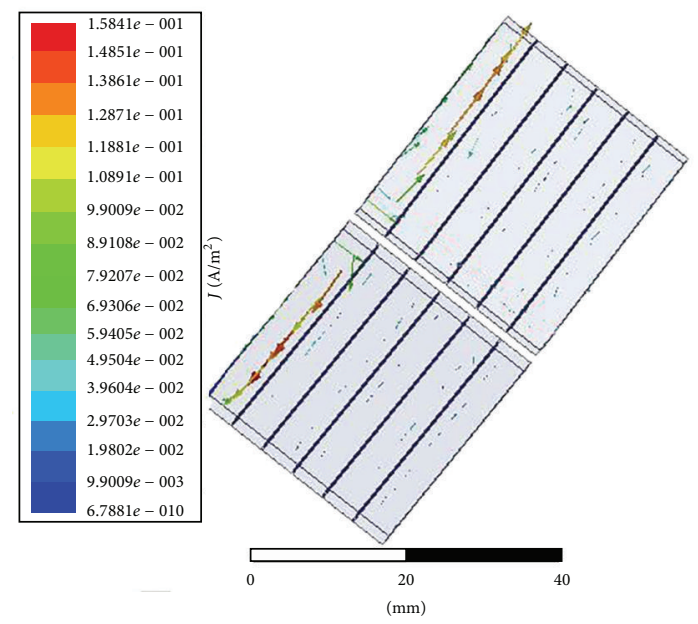

(f)

FIGURE 3: (a) Eddy current density of a permanent magnet. (b) Eddy current density of two-segment permanent magnet. (c) Eddy current density of three-segment permanent magnet. (d) Eddy current density of four-segment permanent magnet. (e) Eddy current density of fivesegment permanent magnet. (f) Eddy current density of six-segment permanent magnet. 
TABLE 3: Eddy current losses of permanent magnet under 37th harmonic currents at different stages.

\begin{tabular}{lcccc}
\hline $\begin{array}{l}\text { Number of } \\
\text { permanent } \\
\text { magnet segments }\end{array}$ & $\begin{array}{c}\text { The ratio of magnetic } \\
\text { length and depth of } \\
\text { penetration }\end{array}$ & $\begin{array}{c}\text { Eddy current losses under } \\
\text { the first and 37th harmonic } \\
\text { excitation/W }\end{array}$ & $\begin{array}{c}\text { Eddy current losses under } \\
\text { the first harmonic } \\
\text { excitation/W }\end{array}$ & $\begin{array}{c}\text { Eddy current losses under } \\
\text { the 37th harmonic } \\
\text { excitation/mW }\end{array}$ \\
\hline 1 & 5.4 & 0.8233 & 0.8024 & 20.9 \\
2 & 2.7 & 0.5187 & 0.5152 & 3.5 \\
3 & 1.8 & 0.3607 & 0.3325 & 28.2 \\
\hline
\end{tabular}

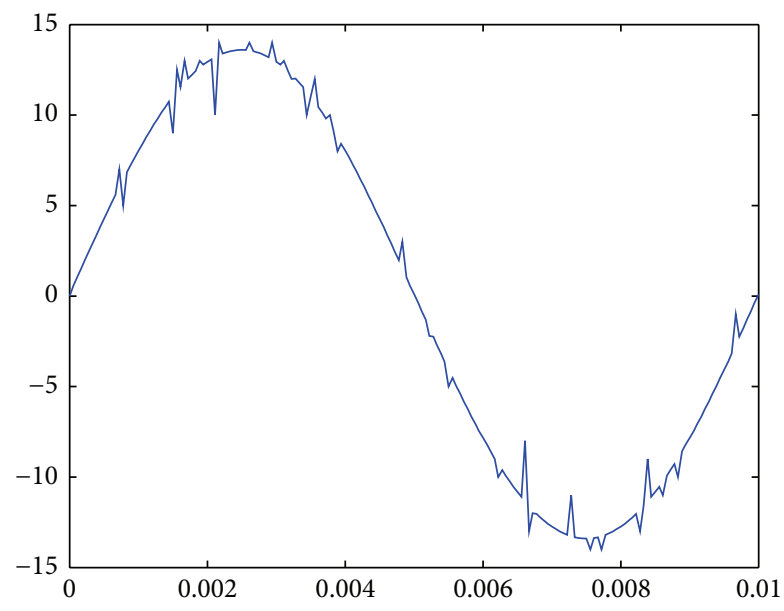

FIGURE 4: Measured current waveform of frequency converter.

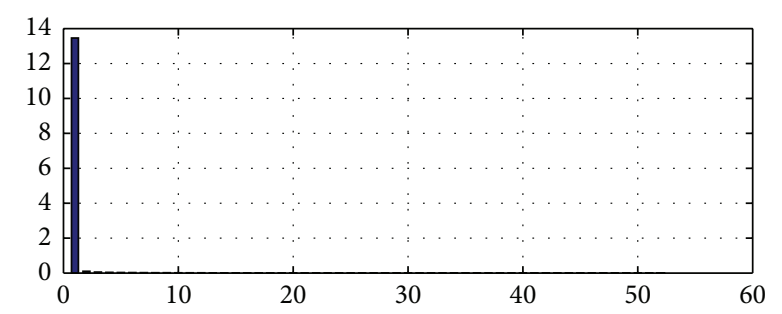

FIGURE 5: Frequency converter output current harmonic analysis.

\section{Calculation and Result Analysis of the Fault}

For the $2.2 \mathrm{~kW}$ permanent magnet synchronous motor, the permanent magnet eddy current loss caused by the space harmonics increased while the number of segments decreased, and the permanent magnet eddy current loss caused by the time harmonics did not increase with the number of segments decreasing. The reason for why the permanent magnet eddy current loss generated by fundamental and 37 th times harmonic increased with the number of segments decreased is that the 37th harmonic current amplitude is smaller and the permanent magnet eddy current loss is mostly generated by fundamental waveform current.

Why did the permanent magnet eddy current loss caused by the space harmonics increase with the number of segments decreasing? The first reason is that the axial split magnetic pole is equivalent to the oblique pole, and the air gap flux density waveform is improved; the other reason is that

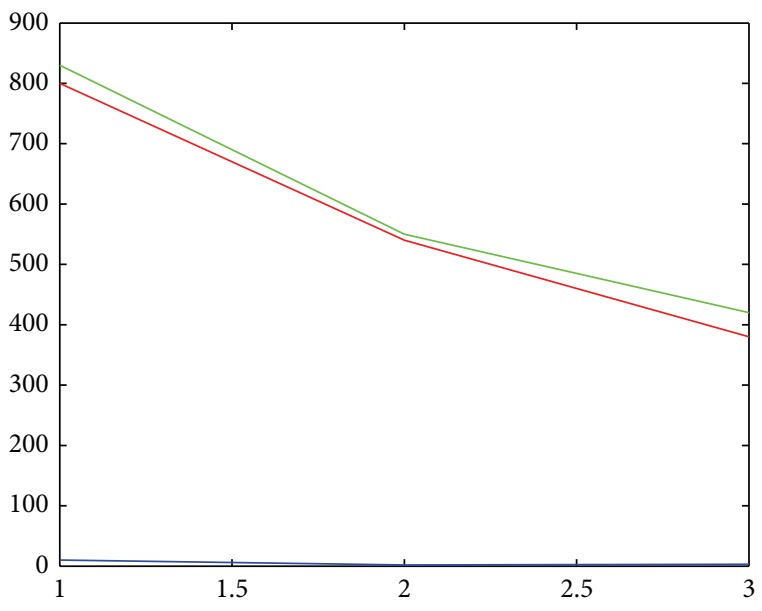

FIGURE 6: Eddy current loss of permanent magnet at different stages.

the sectional pole blocked the formation of eddy current loop, so the permanent magnetic eddy current loss decreased with the increased of number of segments. The source of excitation provided by the inverter contains a large number of harmonic components and higher harmonic amplitude. The depth of penetration of low order harmonic is larger and more than magnetic direction length, so it is not considered. However, the depth of penetration of high order harmonic is smaller and the skin effect is very strong, so permanent magnet eddy current loss produced by time harmonic will have a maximum value.

\section{Conclusions}

The permanent magnet eddy current loss caused by the space harmonics increased with the number of segments decreasing, and the permanent magnet eddy current loss caused by the time harmonics did not increase with the number of segments decreasing. So, when the motor is designed, especially designing the high speed motor, by using the magnet segmentation to reduce the eddy current loss in the magnets, first of all, consider output current waveform of the inverter and pay attention to the ratio between the pole axial length and the penetration depth of high harmonics waveform of current. Lastly, the compromise between cost of segmental magnetic pole and the magnitude of reducing the eddy current loss also needs to be considered; generally the numbers of segments do not exceed 4 . 


\section{Competing Interests}

The authors declare that they have no competing interests.

\section{References}

[1] P. B. Reddy, T. M. Jahns, P. J. McCleer, and T. P. Bohn, "Design, analysis and fabrication of a high-performance fractional-slot concentrated winding surface PM machine," in Proceedings of the 2nd IEEE Energy Conversion Congress and Exposition (ECCE '10), pp. 1074-1081, Atlanta, Ga, USA, September 2010.

[2] Y. Kawase, T. Ota, and H. Fukunaga, "3-D eddy current analysis in permanent magnet of interior permanent magnet motors," IEEE Transactions on Magnetics, vol. 36, no. 4, pp. 1863-1866, 2000.

[3] D. Ishak, Z. Q. Zhu, and D. Howe, "Eddy-current loss in the rotor magnets of permanent-magnet brushless machines having a fractional number of slots per pole," IEEE Transactions on Magnetics, vol. 41, no. 9, pp. 2462-2469, 2005.

[4] W. L. Soong and T. J. E. Miller, "Field-weakening performance of brushless synchronous AC motor drives," IEE Proceedings: Electric Power Applications, vol. 141, no. 6, pp. 331-340, 1994.

[5] M. Nakano, H. Kometani, and M. Kawamura, "A study on Eddy-current losses in rotors of surface permanent-magnet synchronous machines," IEEE Transactions on Industry Applications, vol. 42, no. 2, pp. 429-435, 2006.

[6] W. N. Fu and Z. J. Liu, "Estimation of eddy-current loss in permanent magnets of electric motors using network-field coupled multislice time-stepping finite-element method," IEEE Transactions on Magnetics, vol. 38, no. 2, pp. 1225-1228, 2002.

[7] S. J. Park, H. W. Park, M. H. Lee, and F. Harashima, "A new approach for minimum-torque-ripple maximumefficiency control of BLDC motor," IEEE Transactions on Industrial Electronics, vol. 47, no. 1, pp. 109-114, 2000.

[8] K. Atallah, J. Wang, and D. Howe, "Torque-ripple minimization in modular permanent-magnet brushless machines," IEEE Transactions on Industry Applications, vol. 39, no. 6, pp. 16891695, 2003.

[9] A. G. Jack, B. C. Mecrow, P. G. Dickinson, and D. Stephenson, "Permanent-magnet machines with powdered iron cores and prepressed windings," IEEE Transactions on Industry Applications, vol. 36, pp. 1077-1084, 2003.

[10] B. C. Mecrow, A. G. Jack, J. A. Haylock, and J. Coles, "Faulttolerant permanent magnet machine drives," IEE ProceedingsElectric Power Applications, vol. 143, no. 6, pp. 437-442, 1996.

[11] Z. Q. Zhu and D. Howe, "Instantaneous magnetic field distribution in brushless permanent magnet dc motors, part III: effect of stator slotting," IEEE Transactions on Magnetics, vol. 29, no. 1, pp. 143-151, 1993.

[12] F. Deng, "Commutation-caused eddy-current losses in permanent-magnet brushless DC motors," IEEE Transactions on Magnetics, vol. 33, no. 5, pp. 4310-4318, 1997.

[13] Z. Q. Zhu, K. Ng, N. Schofield, and D. Howe, "Improved analytical modeling of rotor eddy current loss in brushless machines equipped with surfaced- mounted permanent magnets," IEE Proceedings-Electric Power Applications, vol. 151, no. 6, pp. 641650, 2004.

[14] V. Hrabovcová, P. Rafajdus, M. Franko, and P. Hudák, Measurements and Modeling of Electrical Machines, EDIS, Zilina, Slovakia, 2004 (Slovak).
[15] A. G. Jack, B. C. Mecrow, and J. A. Haylock, "A comparative study of permanent magnet and switched reluctance motors for high-performance fault-tolerant applications," IEEE Transactions on Industry Applications, vol. 32, no. 4, pp. 889-895, 1996.

[16] D. Ishak, Z. Q. Zhu, and D. Howe, "Permanent-magnet brushless machines with unequal tooth widths and similar slot and pole numbers," IEEE Transactions on Industry Applications, vol. 41, no. 2, pp. 584-590, 2005.

[17] G. S. Liew, N. Ertugrul, W. L. Soong, and J. Gayler, "Investigation of axial field permanent magnet motor utilising amorphous magnetic material," Australian Journal of Electrical and Electronics Engineering, vol. 3, no. 2, pp. 111-120, 2007.

[18] A. Vagati, P. Guglielmi, M. Pastorelli, and G. Pellegrino, "Position-sensorless control of permanent-magnet-assisted synchronous reluctance motor," IEEE Transactions on Industry Applications, vol. 40, no. 2, pp. 615-622, 2004.

[19] B. J. Chalmers, L. Musaba, and D. F. Gosden, "Variablefrequency synchronous motor drives for electric vehicles," IEEE Transactions on Industry Applications, vol. 32, no. 4, pp. 896903, 1996.

[20] T. Kojima, T. Tanno, K. Maeyama, and H. Okutsu, "Method for manufacturing an axial air-gap electronic motor," U.S. Patent 7 120 986,Oct. 17, 2006.

[21] K. Yamazaki and A. Abe, "Loss investigation of interior permanent-magnet motors considering carrier harmonics and magnet eddy currents," IEEE Transactions on Industry Applications, vol. 45, no. 2, pp. 659-665, 2009. 


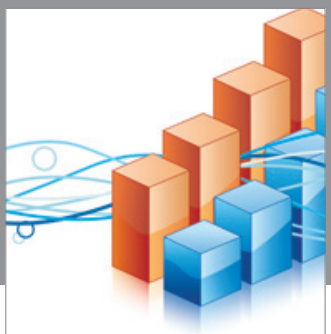

Advances in

Operations Research

vatem alat4

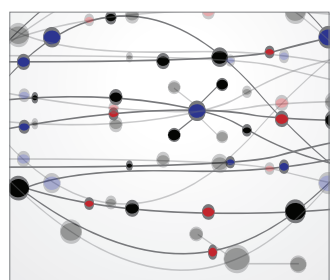

\section{The Scientific} World Journal
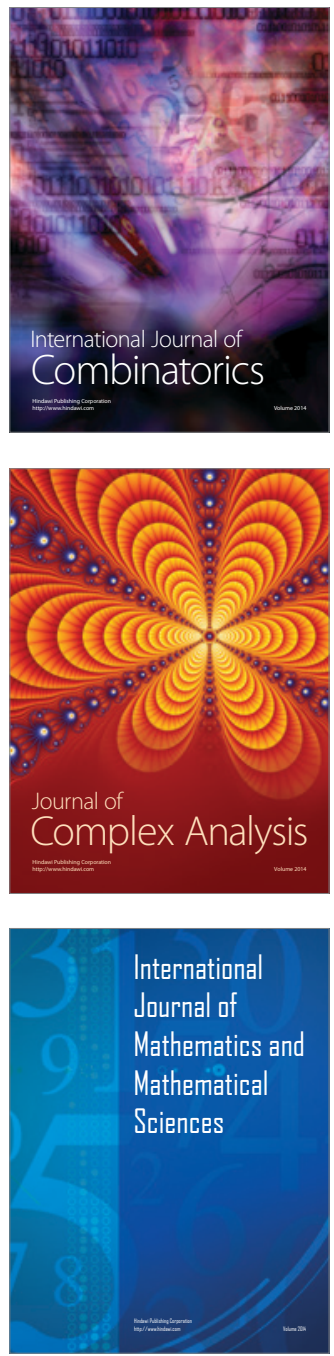
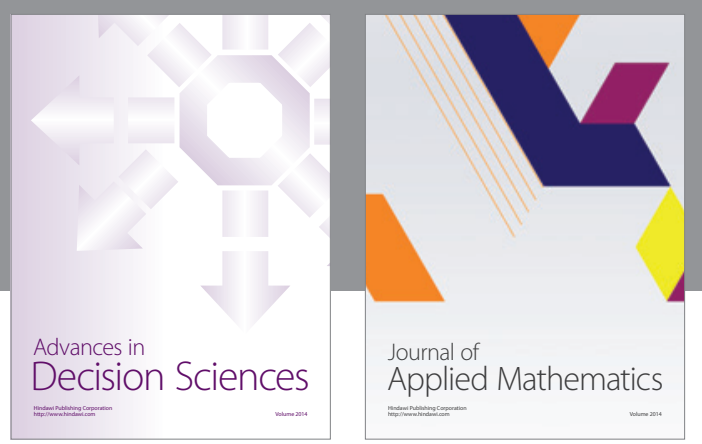

Algebra

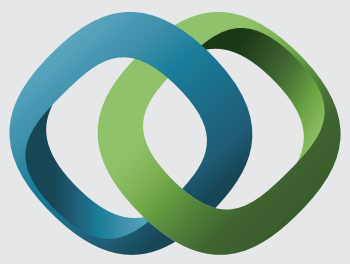

\section{Hindawi}

Submit your manuscripts at

http://www.hindawi.com
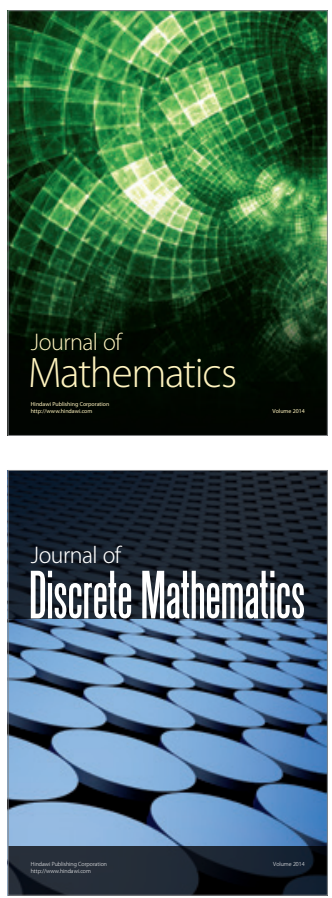

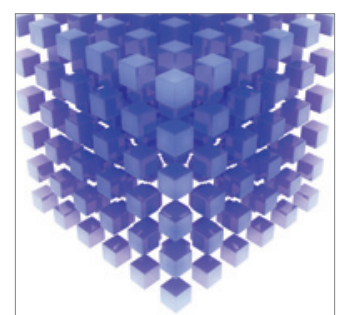

Mathematical Problems in Engineering
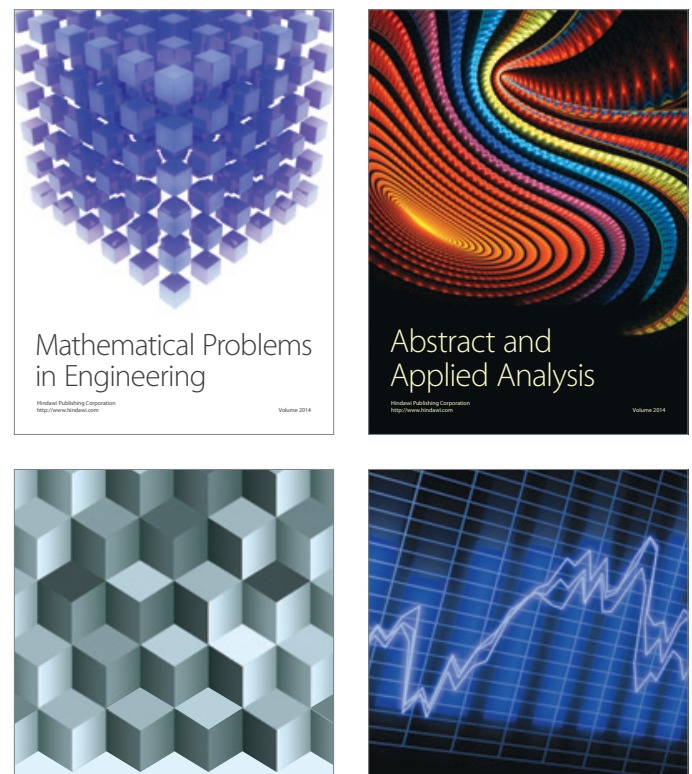

Journal of

Function Spaces

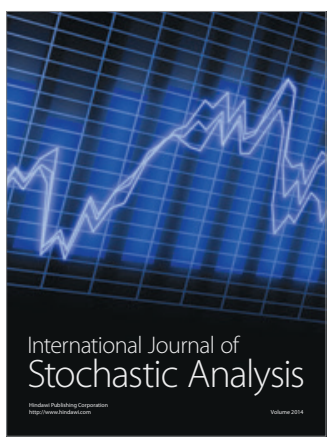

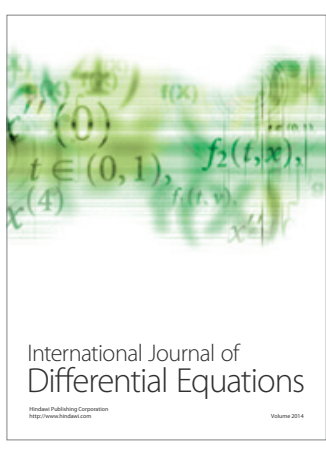
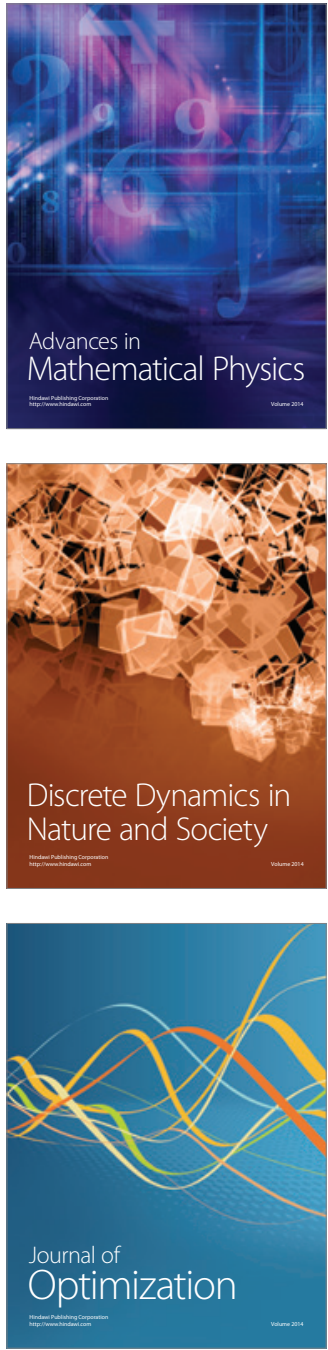